\title{
Loss of Muscarinic $M_{1}$ Receptor Exacerbates Alzheimer's Disease-Like Pathology and Cognitive Decline
}

\author{
Rodrigo Medeiros, ${ }^{* \dagger}$ Masashi Kitazawa, ${ }^{\dagger}{ }^{\dagger}$ \\ Antonella Caccamo, ${ }^{* \dagger}$ David Baglietto-Vargas, ${ }^{* \dagger}$ \\ Tatiana Estrada-Hernandez, ${ }^{\dagger}$ David H. Cribbs, ${ }^{* \neq}$ \\ Avraham Fisher, ${ }^{\S}$ and Frank M. LaFerla* ${ }^{\star \dagger}$ \\ From the Institute for Memory Impairments and Neurological \\ Disorders, ${ }^{*}$ and the Departments of Neurobiology and Behavior, ${ }^{\dagger}$ \\ and Neurology, ${ }^{\ddagger}$ University of California, Irvine, California; and \\ the Israel Institute for Biological Research, ${ }^{\circledR}$ Ness-Ziona, Israel
}

\begin{abstract}
Alzheimer's disease (AD) is pathologically characterized by tau-laden neurofibrillary tangles and $\boldsymbol{\beta}$-amyloid deposits. Dysregulation of cholinergic neurotransmission has been implicated in AD pathogenesis, contributing to the associated memory impairments; yet, the exact mechanisms remain to be defined. Activating the muscarinic acetylcholine $M_{1}$ receptors $\left(M_{1} R s\right)$ reduces $A D$-like pathological features and enhances cognition in AD transgenic models. To elucidate the molecular mechanisms by which $M_{1}$ Rs affect AD pathophysiological features, we crossed the 3xTgAD and transgenic mice expressing human Swedish, Dutch, and Iowa triple-mutant amyloid precursor protein (Tg-SwDI), two widely used animal models, with the $M_{1} R^{-/-}$mice. Our data show that $M_{1} R$ deletion in the $3 \times T$ TgAD and Tg-SwDI mice exacerbates the cognitive impairment through mechanisms dependent on the transcriptional dysregulation of genes required for memory and through acceleration of AD-related synaptotoxicity. Ablating the $M_{1} R$ increased plaque and tangle levels in the brains of 3xTgAD mice and elevated cerebrovascular deposition of fibrillar A $\beta$ in Tg-SwDI mice. Notably, tau hyperphosphorylation and potentiation of amyloidogenic processing in the mice with $A D$ lacking $M_{1} R$ were attributed to changes in the glycogen synthase kinase $3 \beta$ and protein kinase $C$ activities. Finally, deleting the $M_{1} R$ increased the astrocytic and microglial response associated with $A \beta$ plaques. Our data highlight the significant role that disrupting the $M_{1} R$ plays in exacerbating AD-related cognitive decline and pathological features and provide critical preclinical
\end{abstract}

evidence to justify further development and evaluation of selective $M_{1} R$ agonists for treating AD. (Am J Pathol 2011, 179:980-991; DOI: 10.1016/j.ajpath.2011.04.041)

Alzheimer's disease (AD) is a progressive neurodegenerative disorder that leads to cognitive impairment and dementia. The neuropathological hallmarks of $A D$ are amyloid plaques, composed of $\beta$-amyloid (A $\beta$ ) peptides, and neurofibrillary tangles, composed of the hyperphosphorylated tau protein. The deposition of fibrillar $A \beta$ in the cerebrovasculature, a condition known as cerebral amyloid angiopathy (CAA), is also a prominent feature of AD. Together with associated processes, such as inflammation and oxidative stress, these pathological cascades contribute to loss of synaptic integrity and progressive neurodegeneration. ${ }^{1}$

Restoring cholinergic dysfunction has been a primary means of improving the cognitive decline in $A D$ because four of the five Food and Drug Administration-approved drugs are acetylcholinesterase inhibitors, with the notable exception of memantine. ${ }^{2}$ Acetylcholinesterase inhibitors provide mild symptomatic relief but eventually lose efficacy over time, most likely because they are not disease-modifying agents. ${ }^{1}$ Alternatively, recent evidence ${ }^{3,4}$ indicates that stimulation of muscarinic acetylcholine receptors, in particular the $M_{1}$ receptor $\left(M_{1} R\right)$, restores cognition and attenuates AD-like pathological features in several different animal models, rendering it an attractive therapeutic approach for AD. The $M_{1} R$ is the most abundant muscarinic acetylcholine receptor subtype in the cerebral cortex and hippocampus, the two main brain re-

Supported by grants from the NIH (NIH/NIAMS K99AR054695 to M.K.; NIH/NIA R01AG20335 and Program Project AG00538 to F.M.L.).

Accepted for publication April 22, 2011.

Supplemental material for this article can be found at http://ajp. amjpathol.org or at doi: 10.1016/j.ajpath.2011.04.041.

Current address of A.C., Department of Physiology, University of Texas Health Science Center at San Antonio, San Antonio, Texas.

Address reprint requests to Frank M. LaFerla, Ph.D., Institute for Memory Impairments and Neurological Disorders and the Department of Neurobiology and Behavior, University of California, Irvine, 3212 Biological Sciences III, Irvine, CA 92697-4545. E-mail: laferla@uci.edu. 
gions that develop amyloid plaques and neurofibrillary tangles. ${ }^{5}$ Although some studies have demonstrated that the abundance of $M_{1} R$ remains relatively unchanged, other reports have shown reduced and elevated $M_{1} R$ levels in the AD brain. ${ }^{6-10}$ Such discrepancies arise from differences in the handling of the samples, the brain regions selected for study, and the method of measuring receptor binding. Corrections for regional brain atrophy and the relative involvement of receptor subtypes are often undefined. Thus, additional studies are necessary to clarify how the activity and levels of $M_{1} R$ are changed in the AD brain.

Preclinical data have demonstrated that activation of $\mathrm{M}_{1} \mathrm{R}$ elevates soluble amyloid precursor protein (APP) $\alpha$, decreases $A \beta$ and tau pathological features, and blocks $A \beta$-induced neurotoxicity in vitro. ${ }^{11-14}$ Also, treatment with the selective $M_{1} R$ agonist AF267B reduces the $A \beta$ levels in the cerebrospinal fluid and cerebrovasculature in rabbits. ${ }^{15,16}$ Evidence from our laboratory shows that long-term treatment with this compound reverses cognitive impairments and decreases $A \beta$ and tau pathological features in the $3 \times \operatorname{TgAD}$ mice. ${ }^{17}$ Similarly, the administration of the muscarinic agonist RS86 to rats decreases APP levels in the cortex and hippocampus and increases the APP $\alpha$ level in the cerebrospinal fluid. ${ }^{18,19}$ Corroborating these findings, genetic deletion of $M_{1} R$ has recently increased $A \beta$ pathological features in $\mathrm{APP}_{\text {Swe/lnd }}$ mice. ${ }^{20}$ Because of the beneficial effects of $M_{1} R$ agonists in transgenic models, additional studies are necessary to establish the molecular mechanisms through which $M_{1} R$ promotes its neuroprotective effect to justify the translational applicability of using $M_{1} R$ agonists as a therapeutic intervention for $\mathrm{AD}$.

To determine the effect of modulating $M_{1} R$ function on the progression of $A \beta$ and tau pathological features and the subsequent effects on cognition, we evaluated the consequences of ablating $M_{1} R$ signaling in the 3xTgAD mice by crossing them with mice with a null mutation of the $M_{1} R$ gene. ${ }^{21}$ We also assessed the molecular mechanisms by which ablation of $M_{1} R$ affects cerebral microvascular accumulation of $A \beta$ in the transgenic mice expressing human Swedish, Dutch, and lowa triple-mutant APP (Tg-SwDI), a well-described animal model of CAA. ${ }^{22}$

\section{Materials and Methods}

\section{Animals}

Homozygous $M_{1} R^{-1-}$ mice ${ }^{21}$ were bred with either homozygous 3xTgAD mice harboring a PS1 ${ }_{M 146 V}$ knock-in and $\mathrm{APP}_{\text {Swe }}$ and tau $\mathrm{P}_{\mathrm{P} 01 \mathrm{~L}}$ transgenes ${ }^{23}$ or heterozygous Tg-SwDI mice that contain the Swedish and the vasculotropic Dutch and lowa APP mutations. ${ }^{22}$ The offspring were intercrossed to yield 3xTgAD ${ }^{+/+} / M_{1} R^{-/-}\left(3 \times T g A D-M_{1} R^{-/-}\right)$ mice and Tg-SwDI ${ }^{+/-} / \mathrm{M}_{1} \mathrm{R}^{-/-}\left(\mathrm{Tg}-\mathrm{SwDI}-\mathrm{M}_{1} \mathrm{R}^{-/-}\right)$mice. Nine-month-old Tg-SwDI and Tg-SwDI-M $\mathrm{M}_{1} \mathrm{R}^{-/-}$mice and 18-month-old 3xTgAD and 3xTgAD-M $\mathrm{R}_{1} \mathrm{R}^{-1-}$ mice were used in the experiments. Age-matched nontransgenic (nTg) and $\mathrm{M}_{1} \mathrm{R}^{-1-}$ mice were used as controls. All animals had a C57Bl6/129SvJ background. No obvious histological changes were apparent in the brains of mice lacking the
$M_{1} R$. In addition, no changes in the expression levels and distribution of acetylcholine receptors $M_{2}-M_{5}$ were found in $\mathrm{M}_{1} \mathrm{R}^{-l-}$ mice compared with $\mathrm{nTg}$ mice. Behavioral, neuropathological, and neurochemical changes in $\mathrm{M}_{1} \mathrm{R}^{-1-}$ mice have been reviewed elsewhere. ${ }^{4}$ All procedures used in the present study followed the Principles of Laboratory Animal Care from NIH publication 85-23 and were approved by the University of California, Irvine, Institutional Animal Care and Use Committee.

\section{Open Field}

For open field activity testing, mice were individually placed in the center of a novel open field environment (45 $\times 45 \times 30 \mathrm{~cm}$ ) and allowed to explore for 5 minutes. The total distance moved in the open field was monitored with the EthoVision XT video-tracking system (Noldus Information Technology, Leesburg, VA).

\section{Social Recognition}

Each mouse was housed individually for 4 days to establish territorial dominance. A juvenile male mouse was used as the intruder. To test for social recognition, the intruder was placed inside a wire cylinder and introduced into the test cage. In the habituation session, mice were allowed to explore the empty wire cylinder for 10 minutes. Subsequently, the intruder mouse was placed into the cylinder and the tested mouse was allowed to freely explore it for 5 minutes. The entire procedure was repeated five times. After the fifth exposure to the same intruder, a novel intruder was added to the wire cylinder. The experiment was videotaped, and the social interaction was measured as the amount of time that animals spent sniffing through the holes of the cylinder (latency).

\section{Novel Object Recognition}

Before testing, each mouse was habituated to an empty Plexiglas arena $(45 \times 25 \times 20 \mathrm{~cm})$ for 3 consecutive days. On the first day of testing, mice were exposed to two identical objects placed at opposite ends of the arena for 5 minutes. Twenty-four hours later, mice were presented for 5 minutes with one of the familiar objects and a novel object of similar dimensions. The arena and the stimulus objects were cleaned thoroughly between trials to ensure the absence of olfactory cues. If an animal did not explore both objects during the training phase, the test was not scored during the test phase. In the scoring procedure, because some mice exhibited freezing or fearful behavior on introduction to the chamber, scoring did not start until the mice physically moved from their initial starting position, which was always in the corner closest to the familiar object. Exploration counted if the mouse's head was within $2.54 \mathrm{~cm}$ of the object, with its neck extended and vibrissae moving. Simple proximity, chewing, or standing on the object did not count as exploration. All exploratory segments and tests were videotaped for scoring purposes. The recognition index represents the percentage of the time that mice spend exploring the novel object. 


\section{Morris Water Maze}

The apparatus used for the water maze task was a circular aluminum tank (1.2-m diameter) painted white and filled with water maintained at $22^{\circ} \mathrm{C} \pm 2^{\circ} \mathrm{C}$ (mean \pm SEM). The tank was located in a test room containing various prominent visual cues. To reduce stress, mice were placed on the platform for 10 seconds before the first training trial. Mice were trained to swim to a $14-\mathrm{cm}$ diameter circular clear Plexiglas platform submerged 1.5 $\mathrm{cm}$ beneath the surface of the water and invisible to the mice while swimming. The platform was located in a fixed position, equidistant from the center and the wall of the tank. Mice were subjected to four training trials per day (intertrial interval, 5 minutes). During each trial, mice were placed into the tank at one of four designated start points in a pseudorandom order. Mice were allowed to find and escape onto the submerged platform. If they failed to find the platform within 60 seconds, they were manually guided to the platform and allowed to remain there for 10 seconds. Mice were trained for as many days as needed to reach the training criterion of 25 seconds (escape latency). To control for overtraining, probe trials were run for each group, both as soon as they reached group criterion and after all groups had reached criterion. However, the training session was interrupted if mice did not reach the training criterion within 8 days. The probe trial was assessed 24 hours after the last training session and consisted of a 60-second free swim in the pool without the platform. Performance was monitored with the EthoVision XT video-tracking system.

\section{Contextual Fear Conditioning}

During training, mice were placed in the fear conditioning chamber (San Diego Instruments, San Diego, CA) and allowed to explore for 2 minutes before receiving three electric foot shocks (duration, 1 second; intensity, 0.2 $\mathrm{mA}$; intershock interval, 2 minutes). Animals were returned to the home cage 30 seconds after the last foot shock. Twenty-four hours later, behavior in the conditioning chamber was video recorded during 5 minutes and subsequently analyzed for freezing, which was defined as the absence of all movement except for respiration.

\section{Tissue Preparation}

Mice were deeply anesthetized with sodium pentobarbital and euthanized by perfusion transcardially with 0.1 mol/L PBS solution ( $\mathrm{pH} 7.4)$. The right brain hemispheres were fixed for 48 hours in $4 \%$ paraformaldehyde and cryoprotected in 30\% sucrose for immunohistochemical (IHC) analysis. Frozen brains were sectioned coronally into $40 \mu \mathrm{mol} / \mathrm{L}$ sections using a Leica SM2010R freezing microtome (Leica Microsystems, Bannockburn, IL), serially collected in cold $0.02 \%$ sodium azide, and stored at $4^{\circ} \mathrm{C}$. The left hemispheres were snap frozen on dry ice and subject to protein extraction sequentially using the T-PER tissue protein extraction reagent (Thermo Scientific, Rockford, IL) and 70\% formic acid. The supernatant was divided and stored at $-80^{\circ} \mathrm{C}$. The protein concen- tration in the supernatant was determined using the Bradford assay.

\section{Immunoblotting}

Equal protein amounts were separated on a $4 \%$ to $12 \%$ SDS-PAGE gradient, transferred to a nitrocellulose membrane, and incubated overnight with primary antibody at $4^{\circ} \mathrm{C}$. The following primary antibodies were used in this study: c-Fos (9F6) (1:1000), cAMP response element binding (CREB; 48H2) (1:1000), p-CREB (S133) (87G3) (1: 1000), p-glycogen synthase kinase (GSK) $3 \beta$ (S9) (5B3) (1:3000), postsynaptic density protein 95 (PSD-95, 1:1000) (Cell Signaling Technology, Danvers, MA), human APPCT20 (751-770) (1:5000), disintegrin and metalloproteinase domain-containing protein (ADAM)10 (735-749) (1:1000), ADAM17 (TACE, 807-823) (1:1000), $\beta$-site APP cleaving enzyme (BACE) 1 (485-501) (1:1000), GSK3 $\alpha \beta$ (1H8) (1: 1000), CDK5 (268-283) (1:1000) (Calbiochem, San Diego, CA), human tau (HT7) (159-163) (1:5000), phospho-tau AT8 (p-S202/T205) (1:1000), p-tau AT100 (p-S212/T214) (1: 1000), p-tau AT270 (p-T181) (1:1000) (Thermo Scientific), p-tau paired helical filament (PHF)-1 (p-S396/S404) (1: 1000) (a gift from Dr. Peter Davies, Albert Einstein College of Medicine, Manhasset, NY), A 11-16 (6E10) (1:1000) (Covance Research Products, Denver, PA), PP2A (FL-309) (1: 1000), p35 (N-20) (1:200), and glyceraldehyde-3-phosphate dehydrogenase (FL335) (1:5000) (Santa Cruz Biotechnology, Santa Cruz, CA). After washing, the membranes were incubated with adjusted secondary antibodies coupled to horseradish peroxidase. The immunocomplexes were visualized using the SuperSignal West Pico Kit (Thermo Scientific). Band density measurements were obtained using ImageJ 1.36b imaging software $(\mathrm{NIH}$, Bethesda, MD).

\section{ELISA Analyses}

For the determination of $A \beta$ levels, T-PER soluble fractions were loaded directly onto enzyme-linked immunosorbent assay (ELISA) plates, whereas the formic acid supernatants (insoluble fractions) were diluted 1:20 in a neutralization buffer $(1 \mathrm{~mol} / \mathrm{L}$ Tris base and $0.5 \mathrm{~mol} / \mathrm{L}$ $\mathrm{NaH}_{2} \mathrm{PO}_{4}$ ) before loading. MaxiSorp immunoplates (Nunc, Rochester, NY) were coated with mAb20.1 antibody (a gift from Dr. William E. Van Nostrand, Stony Brook University, Stony Brook, NY) at a concentration of $25 \mu \mathrm{g} / \mathrm{mL}$ in coating buffer (0.1 mol/L $\mathrm{Na}_{2} \mathrm{CO}_{3}, \mathrm{pH}$ 9.6) and blocked with $3 \%$ bovine serum albumin (BSA). Standard solutions for both $A \beta_{40}$ and $A \beta_{42}$ were made in the antigen capture buffer $\left(20 \mathrm{mmol} / \mathrm{L} \mathrm{NaH}_{2} \mathrm{PO}_{4}, 2 \mathrm{mmol} / \mathrm{L}\right.$ EDTA, $0.4 \mathrm{~mol} / \mathrm{L} \mathrm{NaCl}, 0.05 \%$ 3-[(3-cholamidopropyl)dimethylammonio]propanesulfonate, and 1\% BSA, pH 7.0) and loaded onto ELISA plates in duplicate. Samples were then loaded (in duplicate) and incubated overnight at $4^{\circ} \mathrm{C}$. Plates were then washed and probed with either horseradish peroxidase-conjugated anti-A $\beta_{40}(\mathrm{C} 49)$ or anti-A $\beta_{42}$ (D32) (a gift from Dr. Vitaly Vasilevko and Dr. David $H$. Cribbs, University of California, Irvine) overnight at $4^{\circ} \mathrm{C}$. The chromogen was 3,3',5,5'-tetramethylbenzidine, and the reaction was discontinued with $30 \%$ phosphoric acid. The 
plates were read at $450 \mathrm{~nm}$ using a plate reader (Molecular Dynamics, Sunnyvale, CA). The readings were then normalized to protein concentrations of the samples.

The levels of tumor necrosis factor- $\alpha$ and IL-1 $\beta$ in the T-PER soluble fractions were measured using commercially available ELISA kits (Thermo Scientific), according to the manufacturer's instructions.

\section{IHC Analyses}

Antigen retrieval was optimized using a $90 \%$ formic acid solution for 7 minutes for $A \beta$ staining. Free-floating sections were pretreated with $3 \%$ hydrogen peroxide and 10\% methanol in Tris-buffered saline (TBS) for 30 minutes to block endogenous peroxidase activity. After a TBS wash, sections were incubated once in $0.1 \%$ Triton X-100 (Fisher Scientific, Pittsburgh, PA) in TBS for 15 minutes and once with $2 \%$ BSA in $0.1 \%$ Triton-X in TBS for 30 minutes. Sections were then incubated overnight at $4^{\circ} \mathrm{C}$ with anti-A $\beta 1-16$ (6E10) (1:1000) (Covance Research Products), anti-phospho-tau AT100 (phospho-S212/ T214) (1:1000) (Thermo Scientific), anti-glial fibrillary acidic protein (GFAP; Millipore, Billerica, MA), or antiCD45 (IBL-3/16) (AbD Serotec, Raleigh, NC) with 5\% normal serum in TBS. After the appropriate biotinylated secondary antibody (1:200 in TBS, $2 \%$ BSA, and 5\% normal serum), sections were processed using the Vectastain Elite $A B C$ reagent and 3,3'-diaminobenzidine (Vector Laboratories, Burlingame, CA), according to the manufacturer's instructions. Sections were then mounted on gelatin-coated slides, dehydrated in graded ethanol, cleared in xylene, and coverslipped with DPX mounting medium (BDH Laboratory Supplies, Poole, UK).

The immunostaining was assessed at six brain coronal levels. Specifically, six alternate $40-\mu \mathrm{m}$ sections of the brain, with an individual distance of approximately 160 $\mu \mathrm{m}$, were obtained between 1.34 and $2.54 \mathrm{~mm}$ posterior to the bregma. Images of stained hippocampal, entorhinal cortex, and amygdaloid areas were acquired using an Axiocam digital camera and AxioVision 4.6 software connected to an Axioskop 50 microscope (Carl Zeiss Microlmaging, Thornwood, NY). A threshold optical density that best discriminated staining from the background was obtained using Image $1.36 \mathrm{~b}$ imaging software. We captured eight images per section: two in the subiculum, two in the CA1, two in the entorhinal cortex, and two in the amygdala (48 images per mouse).

For GFAP and CD45 analyses, data are reported as the labeled area captured (positive pixels) divided by the full area captured (total pixels). The data represent the average value obtained by the analysis of images of the hippocampus, entorhinal cortex, and amygdala. All histological assessments were performed by an examiner blinded to sample identities.

\section{Immunofluorescence}

Sections were first blocked with $3 \%$ normal serum, $2 \%$ BSA, and $0.1 \%$ Triton $\mathrm{X}-100$ in TBS for 1 hour at room temperature. By using the same buffer solution, sections were incubated overnight at $4^{\circ} \mathrm{C}$ with the following primary antibod- ies: anti-synaptophysin (SVP-38) (1:250) (Sigma-Aldrich, St Louis, MO), anti-A $\beta 1-16$ (6E10) (1:200) (Covance Research Products), anti-collagen IV (1:250) (Fitzgerald Industries International, Acton, MA), anti-GFAP (1:1000) (Dako, Carpentaria, CA), and/or anti-Iba-1 (1:200) (Wako Chemicals, Richmond, VA). Sections were then rinsed and incubated for 1 hour with secondary Alexa Fluor-conjugated antibodies (Invitrogen, Carlsbad, CA) at room temperature. Finally, sections were mounted onto gelatin-coated slides in Fluoromount-G (Southern Biotech, Birmingham, AL) and examined under a Leica DM2500 confocal laser microscope using Leica Application Suite Advanced Fluorescence software (Leica Microsystems).

The immunofluorescence was assessed the same brain coronal levels previously described. Confocal images were acquired by sequential scanning using a $z$ separation of $1 \mu \mathrm{m}$. Three-dimensional reconstruction and three-dimensional-rendered optical sections were generated using Leica Application Suite Advanced Fluorescence software (Leica Microsystems). The vascular $\mathrm{A} \beta$ deposition was determined through the analysis of the colocalization of anti-A $\beta 1-16$ (6E10) and anti-collagen IV in the hippocampus, entorhinal cortex, and amygdala. For each section, images were acquired with equal acquisition parameters for both anti-A $\beta 1-16$ (6E10) and anti-collagen IV. Up to 20 vessels were identified using the $6 \mathrm{E} 10$ label and then were matched to the corresponding collagen IV staining. Image measurements were obtained using Image J 1.36b imaging software. The synaptophysin levels represent the average value obtained by the analysis of images of the hippocampus, entorhinal cortex, and amygdala. The integrated intensity of $6 \mathrm{E} 10$ plus collagen IV represents the average optical densities from all of the merged pixels measured.

\section{Thioflavin S Staining}

Sections were incubated in $0.5 \%$ thioflavin S in 50\% ethanol for 10 minutes, differentiated twice in $50 \%$ ethanol, and washed in PBS solution. Staining was visualized under a confocal microscope. Image measurements were made using Image J 1.36b imaging software. The thioflavin S levels represent the average value obtained by the analysis of images of the hippocampus, entorhinal cortex, and amygdala.

\section{Protein Kinase Assay}

The protein kinase (PK) C and A activity levels were measured using the nonradioactive PK assay kit (Calbiochem), according to the manufacturer's instructions. In brief, a fresh half brain sample was homogenized in icecold $50 \mathrm{mmol} / \mathrm{L}$ Tris- $\mathrm{HCl}(\mathrm{pH}$ 7.5) containing $10 \mathrm{mmol} / \mathrm{L}$ benzamidine, $5 \mathrm{mmol} / \mathrm{L}$ EDTA, and $10 \mathrm{mmol} / \mathrm{L}$ EGTA. Samples were then sonicated four times (10 seconds each) and centrifuged at $100,000 \times g$ for 60 minutes at $4^{\circ} \mathrm{C}$. Fresh supernatant was used for the PK activity assays. The protein concentration in the supernatant was determined using the Bradford assay. The peptide pseudosubstrate RFARKGSLRQKNV that can be phosphorylated by both PKC and PKA was precoated in the plate. A biotinylated monoclonal antibody that recognizes the 
phosphorylated form of the peptide pseudosubstrate was added to the wells and detected using horseradish peroxidase-conjugated streptavidin. The plates were read at $492 \mathrm{~nm}$ using a plate reader (Molecular Dynamics). The readings were then normalized to protein concentrations of the samples. The PKC or PKA activity was directly proportional to the color intensity. The use of specific assay buffer and cofactor provided by the kit enabled us to distinguish PKC and PKA activity.

\section{Statistical Analysis}

All data are expressed as the mean \pm SEM. Statistical evaluation of the results was performed using one- or two-way analysis of variance. After significant analyses of variance, multiple post hoc comparisons were performed using Bonferroni's test. Some data were analyzed using the unpaired $t$-test. The accepted level of significance for the tests was $P<0.05$. All tests were performed using the Statistica software package (StatSoft Inc., Tulsa, OK).

\section{Results}

\section{Loss of $M_{1} R$ Exacerbates the Cognitive Impairment in Mice with $A D$}

To explore the role of $M_{1} R$ in cognition and motor control, 3xTgAD and Tg-SwDI mice were tested in behavior tasks dependent on brain areas mostly affected by AD pathological features. ${ }^{22,23}$ The $M_{1} R^{-1-}$ mice showed an agedependent impairment in cognitive function. At the age of 9 months, $\mathrm{M}_{1} \mathrm{R}^{-1-}$ and $\mathrm{nTg}$ mice demonstrated similar behavioral performance in the water maze, novel object recognition, social recognition, and contextual fear conditioning (see Supplemental Figure $\mathrm{S} 1$ at http://ajp. amjpathol.org). However, 18-month-old $\mathrm{M}_{1} \mathrm{R}^{-/-}$mice performed significantly worse relative to age-matched $\mathrm{nTg}$ mice in all behavior tasks (Figure 1). In addition, $\mathrm{M}_{1} \mathrm{R}^{-1-}$ mice showed robust hyperactivity in the open field arena versus nTg mice (Figure 1F; see also Supplemental Figure $\mathrm{S} 1$ at $h$ ttp://ajp.amjpathol.org). Notably, as previously reported, ${ }^{21,24}$ this effect does not confound the cognitive performance of $M_{1} R$ mutant mice. Taken together, these data demonstrate that the loss of $M_{1} R$ accelerates the progressive cognitive decline associated with aging.

To explore the role of $M_{1} R$ in the cognitive deficits associated with AD-like pathological features, mice were tested in the hippocampal-dependent reference spatial memory version of the water maze. 3xTgAD mice were significantly impaired, as indicated by longer latencies to find the platform in the training session (Figure $1 \mathrm{~A}$ ) and reduced target quadrant preference during the probe trial (Figure 1B) compared with age-matched nTg mice. Of great relevance, the genetic deletion of $M_{1} R$ exacerbates the cognitive deficits in 3XTgAD mice. Although both types of mice were unable to reach the training criterion of 25 seconds in 8 days, 3xTgAD mice presented significantly shorter latencies and a higher preference for the target quadrant than $3 \times T g A D-M_{1} R^{-1-}$ mice (Figure 1, A and B). Similarly, Tg-SwDI mice per-
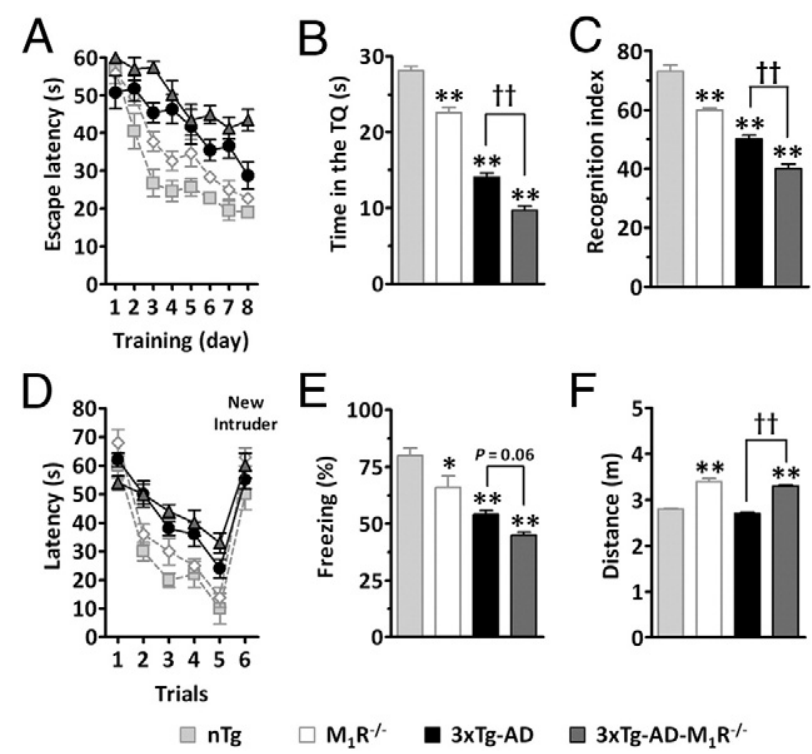

$\mathrm{F}$

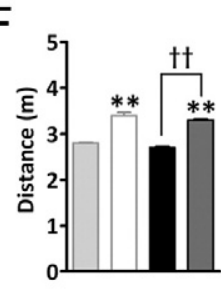

Figure 1. Genetic ablation of $M_{1} R$ disrupts cognitive function. Eighteenmonth-old 3xTgAD mice were tested on a spatial reference version of the Morris water maze (A and $\mathbf{B})$, object recognition $(\mathbf{C})$, social recognition (D), contextual fear conditioning (E), and open field (F) tasks. The cognitive performance of $\mathrm{M}_{1} \mathrm{R}^{-/-}$and 3xTgAD- $\mathrm{M}_{1} \mathrm{R}^{-/-}$mice was significantly impaired when compared with their respective nTg and 3xTgAD littermates. The values represent the mean $\pm \operatorname{SEM}(N=12$ to 15$)$. ${ }^{*} P<0.05$ and ${ }^{* *} P<$ 0.01 compared with nTg mice; ${ }^{\dagger} P<0.01$ compared with $3 \times \mathrm{Tg}$-AD mice. TQ indicates target quadrant.

formed significantly better in the training and probe sections of the water maze than Tg-SwDI-M $\mathrm{M}_{1} \mathrm{R}^{-1-}$ mice (see Supplemental Figure S1 at $h$ ttp://ajp.amjpathol.org).

Novel object recognition has been described as a task primarily dependent on the cortex. Although $\mathrm{nTg}$ mice exhibited a significant increase in the exploration of the nonfamiliar object, both 3xTgAD (Figure 1C) and Tg-SwDI (see Supplemental Figure S1 at http://ajp.amjpathol.org) mice performed poorly compared with nTg mice in their ability to remember the familiar object. Moreover, knockout of the $M_{1} R$ further impairs the novel object recognition in 3xTgAD-M $\mathrm{R}^{-1-}$ and Tg-SwDI- $\mathrm{M}_{1} \mathrm{R}^{-/-}$mice, as indicated by the reduced recognition index compared with 3xTgAD and Tg-SwDI mice, respectively.

The social recognition deficits have been associated with cholinergic decline in a mouse model of AD. As seen for the $\mathrm{nTg}$ mice, repeated exposure to the same intruder results in decreased duration of investigation behavior; thus, the difference in investigation time between the first and subsequent exposures can be used as an index of social recognition memory (Figure 1D; see also Supplemental Figure S1 at http://ajp.amjpathol.org). Deficits in this paradigm of social recognition were observed in both 3xTgAD and Tg-SwDI mice, as indicated by the longer duration of investigation through the trials compared with nTg mice $(P<0.05)$. 3xTgAD-M $\mathrm{R}^{-1-}$ and Tg-SwDI$M_{1} R^{-1-}$ mice exhibited a slightly increased level of interaction to the same intruder mouse on repeated exposures, demonstrating more prominent cognitive impairment than 3xTgAD and Tg-SwDI mice, respectively. Notably, on introducing an unfamiliar mouse, all mice showed a renewed interest in investigation and explored the new intruder as much as they explored the 
original mouse during the first contact. These results indicate that lack of interest in exploring the first intruder on recurring exposure was not attributable to lack of motivation but appears to be because of learning.

Contextual conditioning is an amygdala- and hippocampal-dependent form of learning characterized by the association of a normally innocuous environment or context with an aversive stimulus (in this case, a mild foot shock). Rodents that learn to associate the conditioning chamber with the shock show increased freezing during subsequent exposures to that chamber. During the initial training sessions involving contextual foot-shock pairing, all groups of mice exhibited comparable degrees of freezing (data not shown). However, 3xTgAD (Figure 1E) and Tg-SwDI (see Supplemental Figure S1 at http:// ajp.amjpathol.org) mice manifested a significant deficit in freezing compared with nTg mice in contextual memory when tested 1 day after training. In addition, 3xTgAD$\mathrm{M}_{1} \mathrm{R}^{-/-}$and Tg-SwDI- $\mathrm{M}_{1} \mathrm{R}^{-/-}$mice demonstrated a higher degree of mobility in the conditioning chamber during the probe session compared with 3xTgAD and Tg-SwDI mice, respectively.

\section{Knockout of $M_{1} R$ Disrupts Gene Transcription Required for Memory and Potentiates AD-Related Synaptotoxicity}

To explore the molecular mechanism by which the loss of $M_{1} R$ modulates the age- and AD-dependent cognitive decline, the levels of transcriptional factors c-Fos and $p$-CREB and synaptic proteins PSD-95 and synaptophysin were analyzed. Changes in these neural networks have been associated with memory impairments in $A D$. No changes in the levels of c-Fos, PSD-95, and synaptophysin were found in the brains of 18-month-old $\mathrm{M}_{1} \mathrm{R}^{-/-}$mice compared with $\mathrm{nTg}$ mice, although we detected a significant reduction in $p$-CREB levels (Figure 2, $A, C$, and $D$ ). In addition, we found a significant reduction in the activity of PKA (Figure 2B). More important, no changes were found in $p$-CREB and c-Fos steady-state levels or in PKA activity in the 9-month-old $\mathrm{M}_{1} \mathrm{R}^{-1-}$ mice (data not shown). These data suggest that the memory disruption in 18-month-old $M_{1} R^{-1-}$ mice is a consequence of decreased PKA-CREB signaling activation.

Consistent with behavioral studies, 3xTgAD mice showed a severe dysregulation of c-Fos, $p$-CREB, and PKA and a reduction in the levels of PSD-95 and synaptophysin relative to $\mathrm{nTg}$ mice (Figure 2, A-D). Interestingly, AD-like pathological features in 3xTgAD mice more significantly affected CREB than PKA. The activity of PKA was reduced by $35 \%$, and the phosphorylation of CREB was reduced by $80 \%$, in the 3xTgAD mice. Because $\mathrm{M}_{1} \mathrm{R}^{-1-}$ and 3xTgAD mice showed a comparable degree of disruption in PKA activity, it is possible that AD-like pathological features affect additional pathways that are involved in the regulation of CREB in the 3xTgAD mouse brain. Although it is well accepted that PKA is the major upstream protein associated with CREB phosphorylation, additional PKs (eg, PKB, Akt, and mitogen-activated protein kinase) can exert similar effects on the regulation of CREB activity. ${ }^{25,26}$
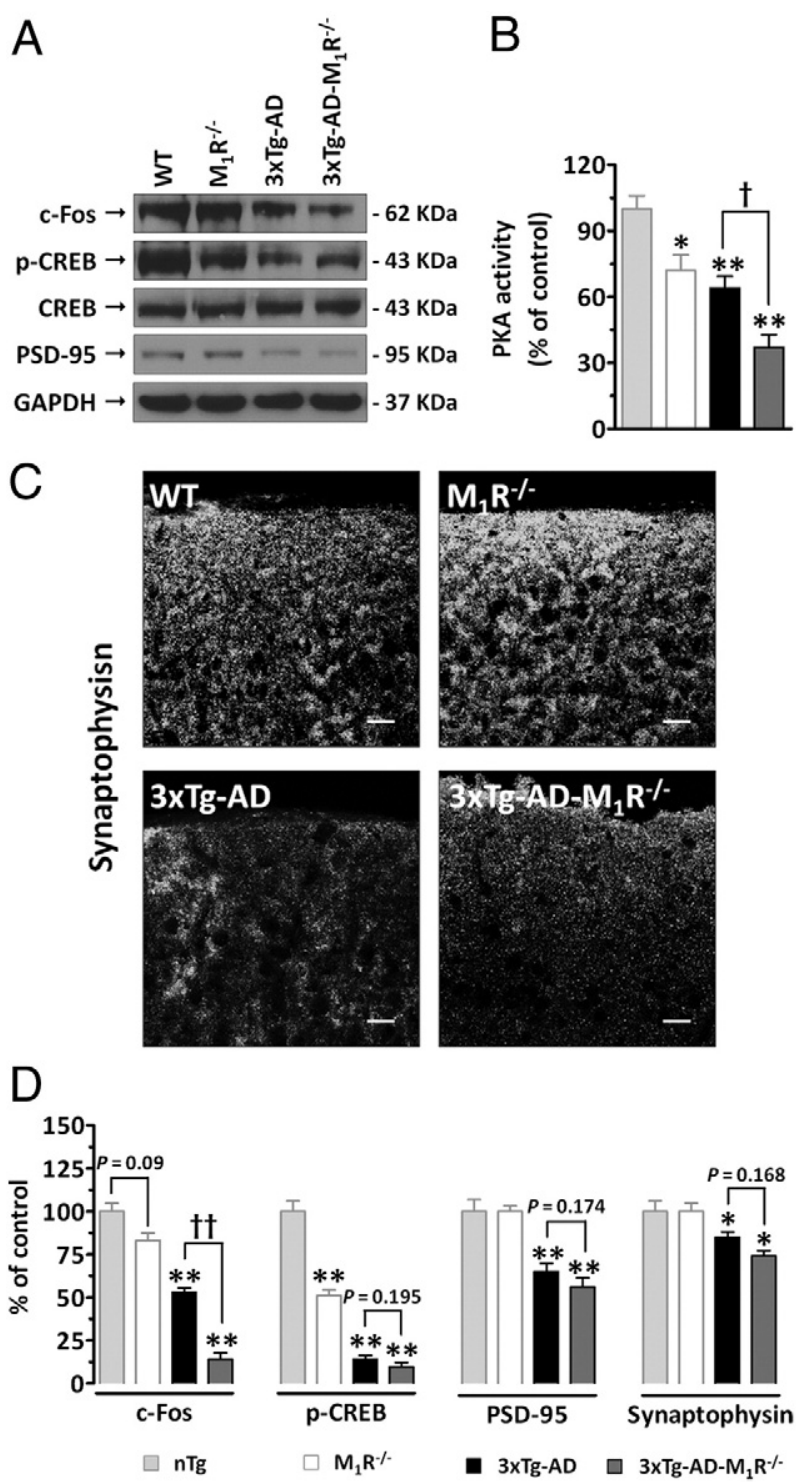

Figure 2. $M_{1} R$ genetic ablation dysregulates memory-related intracellular signaling but not expression of synaptic-related protein. A: Total c-Fos and phosphorylated CREB levels were reduced in the brains of 18-month-old $\mathrm{M}_{1} \mathrm{R}^{-/-}$and 3XTgAD$\mathrm{M}_{1} \mathrm{R}^{-/-}$mice when compared with their respective littermates. B: Similarly, these mice presented disrupted PKA activity. Although 3xTgAD mice show reduced expression of synaptic-associated proteins when compared with nTg mice, no changes were found in the levels of PSD-95 (A) and synaptophysin (C) in mice with an $\mathrm{M}_{1} \mathrm{R}$ deletion. D: Quantification of C-Fos, phosphorylated CREB, PSD-95, and synaptophysin levels. The values represent the mean $\pm \operatorname{SEM}(N=4$ to 6$)$. ${ }^{*} P<0.05$ and ${ }^{\text {*** }} P<0.01$ compared with nTg mice; ${ }^{\dagger} P<0.05$ and ${ }^{\dagger} P<0.01$ compared with $3 \times$ TgAD mice. Scale bar $=25 \mu \mathrm{m}(\mathbf{C})$. GAPDH, glyceraldehyde-3-phosphate dehydrogenase; PSD-95, postsynaptic density protein 95

Notably, deletion of the $M_{1} R$ gene resulted in a marked reduction of c-Fos levels and PKA activity; however, only slight decreases were found in the levels of $p$-CREB, PSD-95, and synaptophysin in 3xTgAD- $M_{1} R^{-1-}$ mice compared with 3xTgAD mice (Figure 2, A-D). The levels of both synaptic proteins were reduced $13 \%$ in these animals compared with 3xTgAD mice. Taken together, these data suggest that defective $M_{1} R$ signaling is responsible for abnormal functioning of the intracellular cascade associated with learning and memory and is likely involved with AD-related synaptotoxicity. 
A

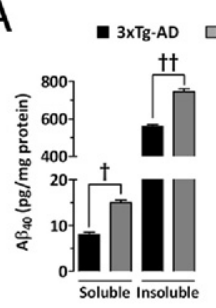

D

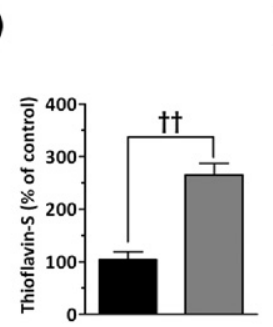

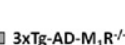
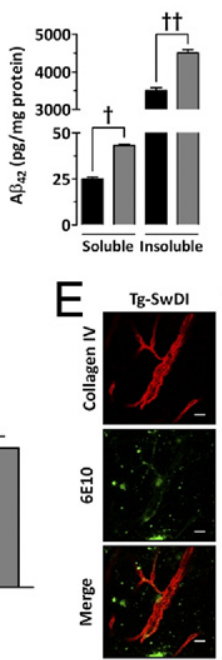

B
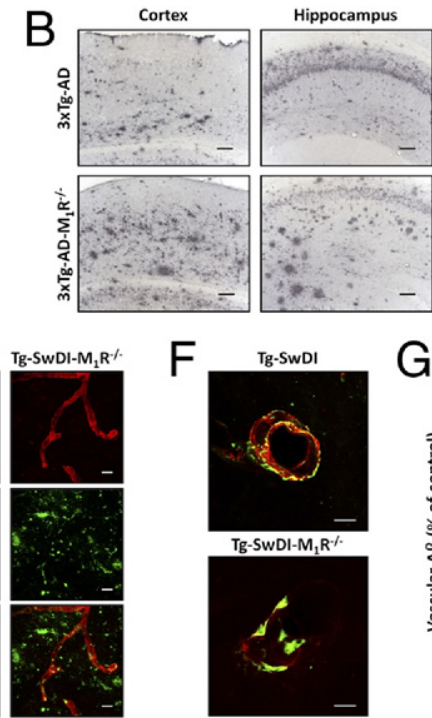

$\mathrm{F}$

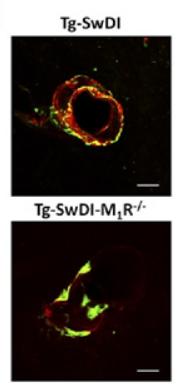

G

$\mathrm{H}$

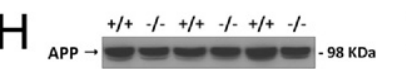
$\mathrm{CPg} \rightarrow$
$\mathrm{Cg} \rightarrow=-$ $\mathrm{C} 83 \rightarrow-1$
$\mathrm{ADAM} 17 \rightarrow-110 \mathrm{KDa}$ ADAM10 $\rightarrow-98 \mathrm{kDa}$ BACE1 $\rightarrow-\cdots--72 \mathrm{KDa}$ GAPDH $\rightarrow=-37 \mathrm{KDa}$
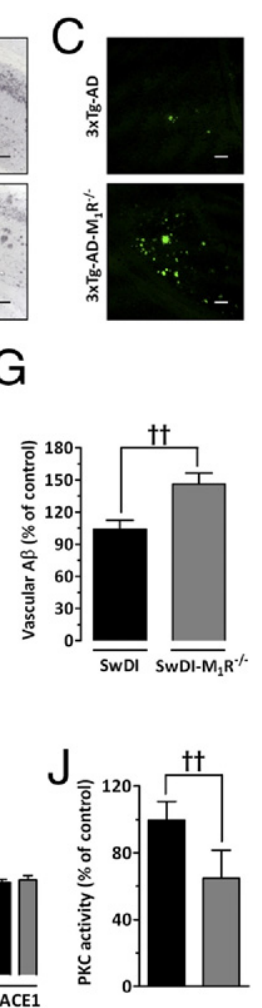

Figure 3. Deletion of $M_{1} R$ accelerates the parenchymal and vascular $\mathrm{A} \beta$ deposition through up-regulation of amyloidogenic APP processing and down-regulation of PKC activity in transgenic mouse models of AD. Eighteen-month-old $3 \times$ TgAD- $\mathrm{M}_{1} \mathrm{R}^{-/-}$mice have higher $\mathrm{A} \beta_{40}$ and $\mathrm{A} \beta_{42}$ levels (A), 6E10 immunoreactivity (B), and thioflavin S-positive plaques (C and $\mathbf{D}$ ) versus 3xTgAD mice. C: The pictures were taken in the subiculum of the hippocampus. $\mathbf{E}$ and $\mathbf{F}$ : Immunofluorescence for collagen IV and 6E10 indicates increased vascular $\mathrm{A} \beta$ deposition in 9-month-old Tg-SwDI- $\mathrm{M}_{1} \mathrm{R}^{-/-}$mice when compared with their littermates. G: Quantification of $\mathrm{A} \beta$ accumulation in the brain vasculature of TgSwDI and Tg-SwDI-M $\mathrm{M}_{1} \mathrm{R}^{-/-}$mice. $\mathbf{H}$ and $\mathbf{I}$ : No changes were found in the expression of human APP transgene, $\alpha$ APP fragment C83, ADAM10, ADAM17, or BACE1 in the brains of 18-monthold 3xTgAD- $\mathrm{M}_{1} \mathrm{R}^{-/-}$mice when compared with $3 \times$ TgAD mice. However, $3 \times$ TgAD- $\mathrm{M}_{1} \mathrm{R}^{-1-}$ mice show increased $\beta$ APP fragment C99 levels. J: $\mathrm{PKC}$ activity is disrupted in the $3 \times$ TgAD $-\mathrm{M}_{1} \mathrm{R}^{-}$ mouse brains. The values represent the mean \pm SEM $(N=4$ to 8$) .{ }^{\dagger} P<0.05$ and ${ }^{\dagger} P<0.01$ compared with $3 \mathrm{xTgAD}$ mice. Scale bars: 100 $\mu \mathrm{m}(\mathbf{B}$ and $\mathbf{C}) ; 50 \mu \mathrm{m}(\mathbf{E}$ and $\mathbf{F})$.

\section{Lack of $M_{1} R$ Increases Parenchymal and Cerebrovascular $A \beta$ Deposition}

The accumulation of $A \beta$ in the brain parenchyma as diffuse and senile plaques and in the cerebral vasculature, a condition known as CAA, is a common pathological feature of $A D .{ }^{1}$ More important, pharmacological and genetic modulations of $M_{1} R$ signaling have been associated with changes in $A \beta$ levels both in vivo and in vitro. ${ }^{17,20}$ Reinforcing this idea, we found that knockout of $M_{1} R$ exacerbates $A \beta$ accumulation in the brain parenchyma of $3 \times T$ TgAD- $M_{1} R^{-1-}$ mice. These animals showed higher levels of $A \beta_{40}$ and $A \beta_{42}$ peptides in both solubleand insoluble-detergent fractions (Figure $3 A$ ), increased 6E10 immunoreactivity (Figure 3B), and increased thioflavin S-positive fibrillar $A \beta$ deposits (Figure $3, C$ and $D$ ) compared with $3 \times \operatorname{TgAD}$ mice. Of great relevance, the loss of $M_{1} R$ was also marked by an extensive acceleration in vascular $A \beta$ deposition in the Tg-SwDI-M $R^{-/-}$ mice relative to the $\mathrm{Tg}-\mathrm{SwDI}$ mice (Figure 3, E-G; see also Supplemental Figure S2 at http://ajp.amjpathol.org). To our knowledge, this is the first evidence indicating that $M_{1} R$ dysfunction leads to increased CAA in a transgenic mouse model of $A D$.

To elucidate the mechanism responsible for the increase in $A \beta$, we determined whether APP processing was altered in $3 \times T g A D-M_{1} R^{-1-}$ and Tg-SwDI- $M_{1} R^{-1-}$ mice. We used the antibody $6 \mathrm{E} 10$ to detect full-length APP and its proteolytic fragments c-terminal APP fragment (CTF) $\beta$ [a 99-amino acid-long CTF produced by $\beta$-secretase cleavage (C99)] and CTF $\alpha$ [an 83-amino acid-long C-terminal APP fragment produced by $\alpha$-secre- tase cleavage (C83)]. The deletion of $M_{1} R$ did not alter APP steady-state levels in the brains of $3 \times \operatorname{TgAD}$ and Tg-SwDI mice. However, the levels of C99, but not C83, were significantly increased in $3 \times \operatorname{TgAD}-\mathrm{M}_{1} \mathrm{R}^{-1-}$ mice (Figure 3, $\mathrm{H}$ and $\mathrm{I}$ ) and Tg-SwDI-M $\mathrm{M}^{-1-}$ mice (see Supplemental Figure S2 at $h$ ttp://ajp.amjpathol.org).

To further explore the mechanism underlying the changes in APP processing, we assessed the levels of $\alpha$-APP-cleaving enzymes ADAM10 and ADAM17 and the putative $\beta$-secretase enzyme BACE1 and the activity of PKC. Notably, PKC activity has been closely related to APP processing. ${ }^{17}$ No changes in the expression of these enzymes were found in 3xTgAD-M $\mathrm{R}_{1}{ }^{-1-}$ and Tg-SwDI$M_{1} R^{-1-}$ mice compared with $3 \times T g A D$ and Tg-SwDI mice, respectively (Figure 3, $\mathrm{H}$ and I; see also Supplemental Figure S2 at $h t t p: / / a j p$. amjpathol.org). However, disruption of $M_{1} R$ signaling was associated with a significant decrease in the activity of PKC in 3xTgAD-M $\mathrm{R}_{1} \mathrm{R}^{-/}$mice (Figure 3J) and Tg-SwDI- $\mathrm{M}_{1} \mathrm{R}^{-1-}$ mice (see Supplemental Figure S2 at http://ajp.amipathol.org). No difference in the PKC activity was observed between $\mathrm{M}_{1} \mathrm{R}^{-/-}$and $\mathrm{nTg}$ mice (data not shown). Taken together, these data show that loss of $M_{1} R$ results in unbalanced APP processing, favoring the amyloidogenic pathway.

\section{Ablating the $M_{1} R$ Gene Accelerates tau Pathological Features}

Previous studies ${ }^{17}$ indicate that pharmacological modulation of $M_{1} R$ directly affects the progression of tau pathological features in 3xTgAD mice. By using this genetic ap- 

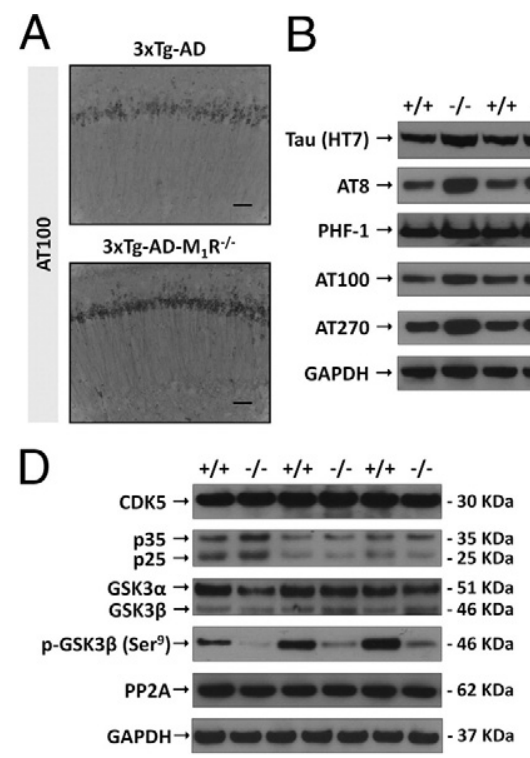

C

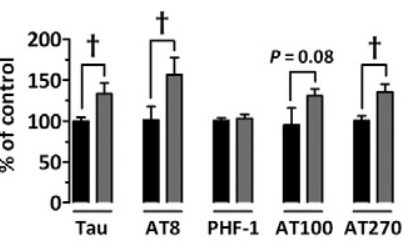

$E$

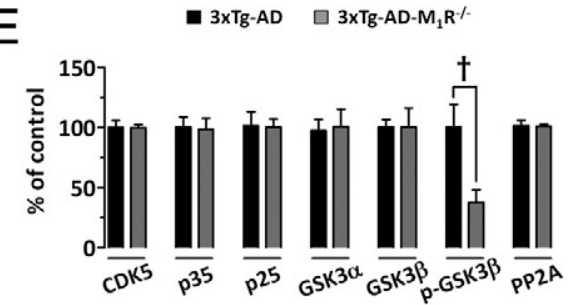

Figure 4. $M_{1} R$ genetic ablation exacerbates $\tau$ pathological features in 3xTgAD mice via GSK3 $\beta$ activation. A: Increased somatodendritic phosphorylated $\tau$ (S212/T214) deposits in 3xTgAD$\mathrm{M}_{1} \mathrm{R}^{-/-}$mice when compared with 3xTgAD mice. IHC was performed with the AT100 antibody. Scale bar $=100 \mu \mathrm{m}$. B and C: Deletion of $\mathrm{M}_{1} \mathrm{R}$ is also associated with higher levels of phosphorylated $\tau$ at residues S199/S202/T205 (AT8) and T181 (AT270) but not at residues S396/S404 (PHF-1). The total $\tau$ level was changed in $3 \times \mathrm{TgAD}-\mathrm{M}_{1} \mathrm{R}^{-/-}$mice when compared with 3xTgAD mice, as indicated by the HT7 immunoblot. D and E: No changes were found in the levels of CDK5, p35/p25, GSK $3 \alpha \beta$, and PP2A. However, 3xTgAD- $\mathrm{M}_{1} \mathrm{R}^{-1-}$ mice present significantly higher levels of activated GSK3 $\beta$ when compared with their littermates, as indicated by the reduction in the phosphorylated GSK3 $\beta$ (S9). The values represent the mean $\pm \operatorname{SEM}(N=5$ to 8$) .{ }^{\dagger} P<0.05$ compared with $3 \times$ TgAD mice. GAPDH indicates glyceraldehyde-3-phosphate dehydrogenase. proach, we more selectively determined the role played by $M_{1} R$ in the maturation of neurofibrillary tangles. Eighteenmonth-old 3xTgAD mice were characterized by a robust accumulation of phosphorylated tau (AT100-positive cells) in the somatodendritic compartments of cortical, amygdaloid, and hippocampal neurons. More important, the removal of $M_{1} R$ exacerbated the phosphorylation of tau at S212 and T214 residues, as indicated by the higher amount of AT100-positive cells in the 3xTgAD-M $R^{-1-}$ mice relative to the $3 x \operatorname{TgAD}$ mice (Figure 4A). Similarly, use of Western blot analysis revealed a significant increase in HT7, AT8, and AT270 immunoreactivity in the brains of $3 \times T g A D-M_{1} R^{-1-}$ mice (Figure $4, B$ and $C$ ).

tau is regulated during both normal homeostasis and stress-induced responses by an array of post-translational modifications, including phosphorylation, a process regulated by various PKs and phosphatases. ${ }^{27}$ No differences in the activation of tau kinase CDK5, evaluated by analyzing levels of p35 and p25, and in the levels of the major tau phosphatase, PP2A, were found between 3xTgAD-M $\mathrm{R}^{-1-}$ and 3xTgAD mice (Figure 4, D and E). On the other hand, a significant increase in the activation of tau kinase GSK3 $\beta$ was found in the animals lacking the $M_{1} R$. GSK3 $\beta$ activation is negatively regulated by phosphorylation at S9. This is consistent with our findings that phosphorylated GSK3 $\beta$ (S9) levels were significantly reduced in $3 \times \operatorname{TgAD}-\mathrm{M}_{1} \mathrm{R}^{-1-}$ mice, thus releasing active GSK3 $\beta$ to hyperphosphorylate tau and facilitate tangle formation. In sum, these data suggest that $M_{1} R$ is a key component in the progression of tau pathological features.

\section{Deletion of $M_{1} R$ Increases Neuroinflammation in Mice with $A D$}

Neuroinflammation is a significant aspect of the pathogenesis of $A D$, characterized by the increased presence of activated glial cells in the brain, which ultimately accelerates neuronal dysfunction and cognitive de- cline. ${ }^{28-30}$ Herein, the progression of AD-like pathological features was characterized by astrogliosis and microgliosis, mainly associated with $A \beta$ plaques, in $3 \times T$ gAD and Tg-SwDI mice compared with nTg mice. Moreover, there were significantly more astrocytes and microglia, as evidenced by the pronounced GFAP and CD45 immunoreactivity, respectively, in the brains of the 3xTgAD- $M_{1} R^{-1-}$ mice (Figure 5, A-C) and the Tg-SwDI$\mathrm{M}_{1} \mathrm{R}^{-1-}$ mice (see Supplemental Figure S3 at http:// ajp.amjpathol.org). More important, the enhanced glial response positively correlated with the higher $A \beta$ load that was present in the $3 \times \operatorname{TgAD}_{\mathrm{A}} \mathrm{M}_{1} \mathrm{R}^{-1-}$ and Tg-SwDI$\mathrm{M}_{1} \mathrm{R}^{-1-}$ mice. Confocal analysis of $3 \times \operatorname{Tg} A D-\mathrm{M}_{1} \mathrm{R}^{-1-}$ and Tg-SwDI- $\mathrm{M}_{1} \mathrm{R}^{-1-}$ mouse brains revealed an increased number of astrocytes (GFAP) and microglia (lba-1) associated with $A \beta$ deposition (Figure 5, D and $E$; see also Supplemental Figure S3 at http://ajp.amjpathol.org). Finally, the loss of $M_{1} R$ was also marked by a significant up-regulation in the levels of cytokines $\mathrm{IL}-1 \beta$ and tumor necrosis factor $\alpha$ in Tg-SwDI-M $\mathrm{M}_{1} \mathrm{R}^{-1-}$ mice relative to Tg-SwDI mice (see Supplemental Figure S3 at http:// ajp.amjpathol.org). These results establish $M_{1} R$ as a critical modulator of neuroinflammation.

\section{Discussion}

Herein, we report the novel findings that ablating the $M_{1} R$ disrupts PKA-CREB signaling, correlating with exacerbation of cognitive impairment. Notably, the dysregulation in cognitive function and transcriptional activity was more prominent in the $3 \times \operatorname{TgAD}-\mathrm{M}_{1} \mathrm{R}^{-1-}$ and Tg-SwDI- $\mathrm{M}_{1} \mathrm{R}^{-1-}$ mice, likely as a consequence of the AD-related synaptotoxicity. Moreover, APP processing was shifted toward the amyloidogenic pathway in mice with $A D$ that lacked the $M_{1} R$, which resulted in increased amyloid deposition and neuroinflammation. 3xTgAD-M $\mathrm{R}^{-1-}$ mice were also marked by a more robust phosphorylation of tau protein than 3xTgAD mice, a process closely associated with GSK3 $\beta$ hyperactivation. The PKC activity, an enzyme 


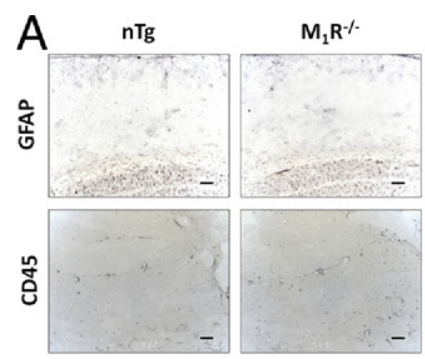

B
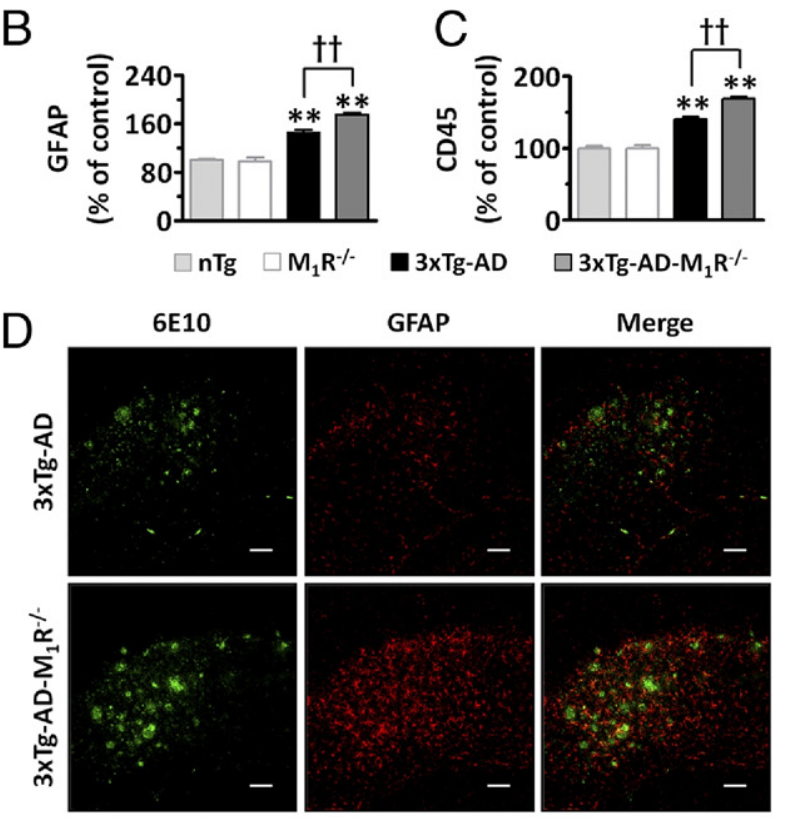

E
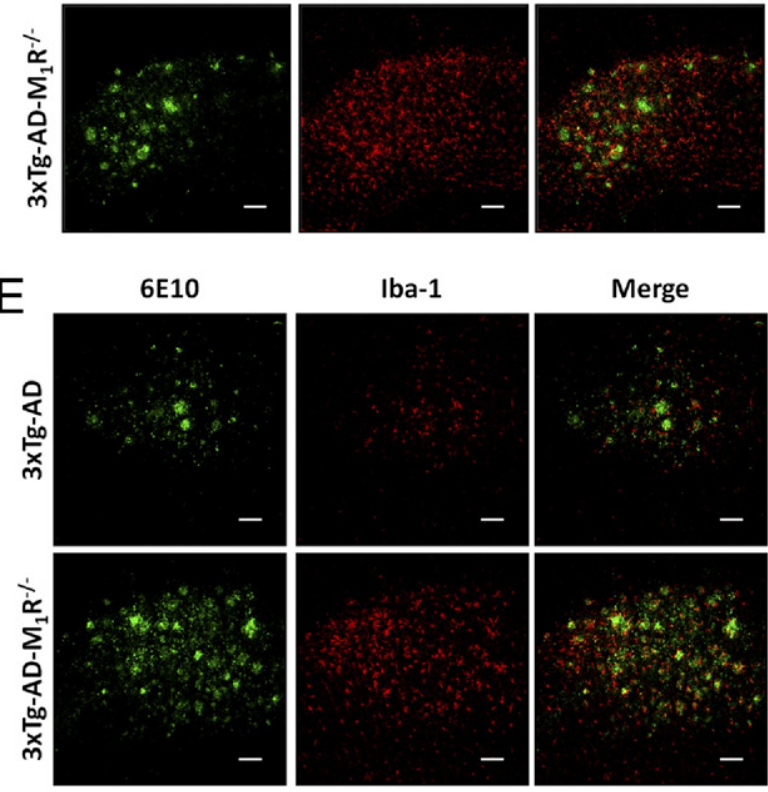

Figure 5. $M_{1} R$ genetic ablation enhances the inflammatory response in $3 \times T g A D$ mice. The number of $\mathrm{GFAP}^{+}(\mathbf{A}$ and $\mathbf{B})$ and $\mathrm{CD}^{4} 5^{+}(\mathbf{A}$ and $\mathbf{C})$ cells was significantly higher in $3 \times \mathrm{TgAD}-\mathrm{M}_{1} \mathrm{R}^{-1-}$ mice when compared with $3 \times \mathrm{xT}$ gAD mice. Colocalization of astrocytes $\left(\mathrm{GFAP}^{+}\right.$cells) (D) and microglia (Iba-1-positive cells) (E) with $\mathrm{A} \beta$ deposits (6E10) in the brains of $3 \mathrm{xTgAD}$ and $3 \times \mathrm{XTgAD}-\mathrm{M}_{1} \mathrm{R}^{-/-}$mice. The values represent the mean $\pm \operatorname{SEM}(N=5)$. ${ }^{* * *} P<0.01$ compared with nTg mice; ${ }^{+} P<0.01$ compared with $3 \times \mathrm{XTAD}$ mice. Scale bar $=100 \mu \mathrm{m}(\mathbf{A}, \mathbf{D}$, and $\mathbf{E})$.

linked with $A \beta$ and tau pathological features, ${ }^{31}$ was significantly reduced in $3 \times \operatorname{TgAD}-\mathrm{M}_{1} \mathrm{R}^{-1-}$ and Tg-SwDI$\mathrm{M}_{1} \mathrm{R}^{-1-}$ mice.

Evidence that $M_{1} R$ is highly expressed in brain areas in which cholinergic synapses are proposed to mediate acquisition and storage of new information has suggested that this receptor is a fundamental player in learning and memory. ${ }^{5,32}$ Advances in understanding the role of $M_{1} R$ in cognition were obtained with the generation of $M_{1} R$-mutant mice. ${ }^{4}$ Miyakawa and colleagues ${ }^{24}$ demonstrated that young $\mathrm{M}_{1} \mathrm{R}^{-1-}$ mice performed as well as their nTg littermates in various hippocampal-dependent tasks but showed some deficits in other tasks that correlated with the degree of hyperactivity displayed. Notably, such a hyperactivity phenotype has been associated with the lack of $M_{1} R$ on inhibitory interneurons in the striatum, where this receptor is normally activated by locally released acetylcholine, resulting in inhibitory projections to dopaminergic neurons in the substantia nigra pars compacta. ${ }^{33,34}$ Moreover, $M_{1} R^{-1-}$ mice showed working memory and consolidation impairment without acquisition deficit in some learning- and memory-dependent tasks. ${ }^{21}$ The genetic deletion of $M_{1} R$ also resulted in electrophysiological deficits and intracellular signaling disruption (eg, mitogen-activated protein kinase activation and phosphoinositide hydrolysis). ${ }^{35,36}$ An outstanding finding of our study is that $\mathrm{M}_{1} \mathrm{R}^{-1-}$ mice developed an age-dependent cognitive decline in tasks in which they were previously reported to be unaffected.

Although many muscarinic effects have been identified in memory circuits, including a diversity of presynaptic and post-synaptic actions in the hippocampus, the identities of the molecular subtypes and the intracellular pathways responsible for any given function remain elusive. ${ }^{37}$ Long-term plastic changes in the brain, including those supporting learning and memory formation, are assumed to depend on permanent functional alterations in neuronal cells that require reprogramming of gene expression. Inducible transcription factors, such as c-Fos and CREB, are supposed to act as messengers in coupling shortterm neuronal activity with changes at the level of gene transcription. ${ }^{38}$ The increase of c-Fos mRNA and/or protein levels has resulted from the action of neurotransmitters on membrane receptors and seems to be induced by physiological stimuli. ${ }^{39}$ CREB, on the other hand, is mainly activated through phosphorylation by several signaling pathways, including PKA. ${ }^{40}$ Impairment of cellular signaling has been implicated in the cognitive deficits in AD. ${ }^{41,42}$ Our study provides clear evidence that deletion of $M_{1} R$ results in impairment of $c-F o s$ and PKA-CREB signaling in aged brain, an effect exacerbated in the AD-like mouse brain. Such data indicate that activation of $M_{1} R$ may be a potential therapeutic alternative to restore learning and memory in aged and AD brains. However, additional studies are necessary to identify the intracellular pathways linked to the regulation of c-Fos and PKACREB and the genes that are modulated by the activation of these transcriptional factors.

Preclinical evidence has highlighted the therapeutic value of targeting the $M_{1} R$ for treating $A D .{ }^{43}$ Previous data indicate that the selective $M_{1} R$ agonist AF267B increases the formation of the $\alpha$-secretase-generated C83 fragment in the brains of young $3 \times T$ T-AD mice, whereas its levels are lower after treatment with the $M_{1} R$ antagonist dicyclomine. Moreover, we reported an increase in the steady-state levels of the $\alpha$-secretase enzyme ADAM17 and a decrease in the BACE1 levels in the brains of AF267B-treated versus untreated 3xTg-AD 
mice. Notably, BACE1 levels were significantly higher in the dicyclomine-treated mice compared with control mice. ${ }^{17}$ Although a change in the steady-state levels does not always reflect changes in activity, these data, together with the changes in the levels of $\beta$-secretase C99 and $\alpha$-secretase C83 fragments and in the A $\beta$ levels, strongly suggest that the effect of $A \beta$ pathological features in 3xTg-AD after $M_{1} R$ agonist treatment are because of a shift in APP processing toward the nonamyloidogenic pathway. This hypothesis was reinforced by the recent findings in the $\mathrm{APP}_{\text {swe/lnd }}$ mice that showed an increase in amyloidogenic APP processing and $A \beta$ accumulation after genetic deletion of $M_{1} R .^{20}$ Of great relevance, our data show, for the first time to our knowledge, that the increase in the $\beta$-secretase C99 fragment and A $\beta$ levels induced by the $M_{1} R$ genetic ablation triggers a pathological cascade that leads to exacerbated microglial and astrocytic activation, synaptic damage, and, ultimately, cognitive failure.

CAA is most commonly observed and prominent in leptomeningeal arteries but also often extends into the microvasculature of the cerebral cortex. Reduced blood flow has been reported as one of the most consistent physiological deficits in $A D$, contributing to ischemic brain injury, intracerebral hemorrhage, and cognitive dysfunction. ${ }^{44-46}$ Evidence ${ }^{22,47}$ suggests that $A \beta$ accumulates in the wall and the perivascular space of cerebral vessels and in the brains of individuals with $A D$ because of its impaired clearance from the brain and/or imbalances between its production and clearance. This idea has been supported by the studies conducted with the Tg-SwDI mice, which develop early-onset and robust cerebral deposition of $A \beta$, mainly in the cerebral microvasculature, because of inefficient $A \beta$ clearance across the blood-brain barrier. ${ }^{22} \mathrm{~A} \beta$ peptides may be produced primarily within neurons; after being secreted into the interstitial space, the interstitial fluids flow into the perivascular space of local arterioles and are then transported opposite to the direction of the blood into larger arteries, where the $A \beta$ is ultimately drained from the brain. ${ }^{48} \mathrm{In}$ terestingly, the $M_{1} R$ agonist AF267B decreased vascular (eg, capillaries and arterioles) and perivascular $\mathrm{A} \beta_{42}$ deposits in the cortex and cerebrospinal fluid of rabbits lesioned by the cholinotoxin M20.4-saporin injected into the nucleus basalis. ${ }^{16}$ Herein, we gained further insights into the mechanisms that drive the $A \beta$ deposition in the cerebrovasculature, showing that stimulation of amyloidogenic APP processing in the Tg-SwDI-M $\mathrm{M}_{1} \mathrm{R}^{-/-}$mice culminates within increased $A \beta$ deposits in the cerebrovasculature. To our knowledge, this is the first report comprehensively showing that reduction of $A \beta$ generation in the brain parenchyma through $M_{1} R$ stimulation may represent a promising feature for inhibiting CAA.

In the diseased brain, tau becomes abnormally hyperphosphorylated, which ultimately causes the microtubules to disassemble; the free tau molecules aggregate into paired helical filaments. Multiple lines of evidence suggest that tau hyperphosphorylation results from perturbation of cellular signaling, mainly through an imbalance in the activities of different PKs and phosphatases. ${ }^{27}$ Herein, we show that $M_{1} R$ specifically modulates the tau phosphorylation through the regulation of GSK3 $\beta$ activity. The increase in tau phosphorylation was selective because we found an increase in phosphorylated tau only at GSK3 $\beta$-targeted residues after the deletion of $M_{1} R$ in the 3xTgAD mice [ie, S202/T205 (detected by antibody AT8), T181 (detected by antibody AT270), and T212/ S214 (detected by antibody AT100)]. ${ }^{49}$ However, we did not find changes in tau phosphorylation at S396/404 (detected by antibody PHF-1). This site seems to be phosphorylated by GSK3 $\beta$ and CDK5; therefore, it is likely that combined activation of both kinases may be necessary to increase phosphorylation of the PHF-1 site. ${ }^{50,51}$ In the 3xTg-AD mice, AT270, AT180, and AT100 represent early markers of tau phosphorylation, whereas reactivity with AT8 and PHF-1 represents mid and late stages. Therefore, the $M_{1} R$ modulates tau phosphorylation at the early and mid stages but not at a late marker, such as PHF-1. These data reinforce the use of $M_{1} R$ agonists as potential disease-modifying therapy for AD. ${ }^{17}$

The present study also provides evidence for the involvement of PKC in the molecular changes induced by $M_{1} R$ loss in mice with $A D$. Notably, recently, disrupted coupling between $M_{1} R$ and $G q$ protein correlated with reductions of PKC activity and $\mathrm{N}$-methyl-D-aspartate receptor density in post-mortem AD brains. ${ }^{52}$ This pathway seems to be activated on appropriate cell stimulation by acetylcholine and participates in an array of important functions within normal cellular physiology, such as regulation of downstream kinases (eg, CDK5 and GSK3 $\beta$ ), nonamyloidogenic APP processing, and memory storage. ${ }^{53-55}$ Indeed, changes in PKC activity have been associated with all major $A D$ neuropathological markers. ${ }^{31}$ Although the identity of the PKC isoenzyme associated with $M_{1} R$ stimulation is still uncertain, most likely the $\mathrm{PKC} \gamma$, which is abundant in the hippocampus and colocalizes with neurons expressing the $M_{1} R$, may be particularly relevant to $M_{1} R$ signaling in $A D .{ }^{56,57}$ However, additional studies are necessary to confirm this hypothesis.

During the past few years, evidence has accumulated that indicates $M_{1} R$ is a feasible therapeutic target for $A D$. However, because of the potential lack of $M_{1} R$ selectivity of several muscarinic agonists tested in previous clinical studies in patients with $A D$, we generated the 3xTgAD$\mathrm{M}_{1} \mathrm{R}^{-1-}$ and Tg-SwDI-M $\mathrm{M}_{1} \mathrm{R}^{-1-}$ mice. Our study using these models clearly shows, for the first time to our knowledge, the involvement of $M_{1} R$ in all key pathological changes found in $A D$ (ie, parenchymal and cerebrovascular amyloid deposition, neurofibrillary tangles, neuroinflammation, and cognitive decline). Remarkably, our transgenic mouse models have great potential for the development of preclinical studies to further evaluate and design selective $M_{1} R$ agonists for treating $A D$. More work is required to fully elucidate the roles of $M_{1} R$ in aging and $A D$ and to further identify downstream target proteins (eg, PKC isoforms). The current results, together with data in the literature, provide clear functional and molecular evidence indicating that the $M_{1} R$ represents a viable strategy for treating $A D$. 


\section{Acknowledgments}

We thank Dr. William E. Van Nostrand (Stony Brook University, Stony Brook, NY) for providing the Tg-SwDI mice and Dr. Katumi Sumikawa (University of California, Irvine, CA) for providing the $M_{1} R^{-1-}$ mice.

\section{References}

1. Querfurth HW, LaFerla FM: Alzheimer's disease. N Engl J Med 2010 , 362:329-344

2. Mangialasche F, Solomon A, Winblad B, Mecocci P, Kivipelto M: Alzheimer's disease: clinical trials and drug development. Lancet Neurol 2010, 9:702-716

3. Fisher A: M1 muscarinic agonists target major hallmarks of Alzheimer's disease: the pivotal role of brain M1 receptors. Neurodegener Dis 2008, 5:237-240

4. Wess J, Eglen RM, Gautam D: Muscarinic acetylcholine receptors: mutant mice provide new insights for drug development. Nat Rev Drug Discov 2007, 6:721-733

5. Levey Al, Kitt CA, Simonds WF, Price DL, Brann MR: Identification and localization of muscarinic acetylcholine receptor proteins in brain with subtype-specific antibodies. J Neurosci 1991, 11:3218-3226

6. Mash DC, Flynn DD, Potter LT: Loss of M2 muscarine receptors in the cerebral cortex in Alzheimer's disease and experimental cholinergic denervation. Science 1985, 228:1115-1117

7. Tsang SW, Lai MK, Kirvell S, Francis PT, Esiri MM, Hope T, Chen CP, Wong PT: Impaired coupling of muscarinic M1 receptors to G-proteins in the neocortex is associated with severity of dementia in Alzheimer's disease. Neurobiol Aging 2006, 27:1216-1223

8. Flynn DD, Ferrari-DiLeo G, Levey Al, Mash DC: Differential alterations in muscarinic receptor subtypes in Alzheimer's disease: implications for cholinergic-based therapies. Life Sci 1995, 56:869-876

9. Shiozaki K, Iseki E, Hino H, Kosaka K: Distribution of $m 1$ muscarinic acetylcholine receptors in the hippocampus of patients with Alzheimer's disease and dementia with Lewy bodies: an immunohistochemical study. J Neurol Sci 2001, 193:23-28

10. Svensson AL, Alafuzoff I, Nordberg A: Characterization of muscarinic receptor subtypes in Alzheimer and control brain cortices by selective muscarinic antagonists. Brain Res 1992, 596:142-148

11. Nitsch RM, Slack BE, Wurtman RJ, Growdon JH: Release of Alzheimer amyloid precursor derivatives stimulated by activation of muscarinic acetylcholine receptors. Science 1992, 258:304-307

12. Sadot E, Gurwitz D, Barg J, Behar L, Ginzburg I, Fisher A: Activation of $\mathrm{m} 1$ muscarinic acetylcholine receptor regulates tau phosphorylation in transfected PC12 cells. J Neurochem 1996, 66:877-880

13. Haring R, Fisher A, Marciano D, Pittel Z, Kloog Y, Zuckerman A, Eshhar N, Heldman E: Mitogen-activated protein kinase-dependent and protein kinase $\mathrm{C}$-dependent pathways link the $\mathrm{m} 1$ muscarinic receptor to beta-amyloid precursor protein secretion. J Neurochem 1998, 71:2094-2103

14. Jones CK, Brady AE, Davis AA, Xiang Z, Bubser M, Tantawy MN, Kane AS, Bridges TM, Kennedy JP, Bradley SR, Peterson TE, Ansari MS, Baldwin RM, Kessler RM, Deutch AY, Lah JJ, Levey Al, Lindsley CW, Conn PJ: Novel selective allosteric activator of the M1 muscarinic acetylcholine receptor regulates amyloid processing and produces antipsychotic-like activity in rats. J Neurosci 2008, 28:1042210433

15. Beach TG, Walker DG, Potter PE, Sue LI, Fisher A: Reduction of cerebrospinal fluid amyloid beta after systemic administration of M1 muscarinic agonists. Brain Res 2001, 905:220-223

16. Beach TG, Walker DG, Potter PE, Sue LI, Scott S, Layne KJ, Newell AJ, Poston ME, Webster SD, Durham RA, Emmerling MR, Honer WG, Fisher A, Roher AE: Immunotoxin lesion of the cholinergic nucleus basalis causes Abeta deposition: towards a physiologic animal model of Alzheimer's disease. Curr Med Chem Immun Endocr Metab Agents 2003, 3:233-243

17. Caccamo A, Oddo S, Billings LM, Green KN, Martinez-Coria H, Fisher A, LaFerla FM: M1 receptors play a central role in modulating AD-like pathology in transgenic mice. Neuron 2006, 49:671-682

18. Lin L, Georgievska B, Mattsson A, Isacson O: Cognitive changes and modified processing of amyloid precursor protein in the cortical and hippocampal system after cholinergic synapse loss and muscarinic receptor activation. Proc Natl Acad Sci U S A 1999, 96:12108-12113

19. Seo H, Ferree AW, Isacson O: Cortico-hippocampal APP and NGF levels are dynamically altered by cholinergic muscarinic antagonist or M1 agonist treatment in normal mice. Eur J Neurosci 2002, 15: 498-506

20. Davis AA, Fritz JJ, Wess J, Lah JJ, Levey Al: Deletion of M1 muscarinic acetylcholine receptors increases amyloid pathology in vitro and in vivo. J Neurosci 2010, 30:4190-4196

21. Anagnostaras SG, Murphy GG, Hamilton SE, Mitchell SL, Rahnama NP, Nathanson NM, Silva AJ: Selective cognitive dysfunction in acetylcholine M1 muscarinic receptor mutant mice. Nat Neurosci 2003 6:51-58

22. Davis J, Xu F, Deane R, Romanov G, Previti ML, Zeigler K, Zlokovic BV, Van Nostrand WE: Early-onset and robust cerebral microvascular accumulation of amyloid beta-protein in transgenic mice expressing low levels of a vasculotropic Dutch/lowa mutant form of amyloid beta-protein precursor. J Biol Chem 2004, 279:20296-20306

23. Oddo S, Caccamo A, Shepherd JD, Murphy MP, Golde TE, Kayed R, Metherate R, Mattson MP, Akbari Y, LaFerla FM: Triple-transgenic model of Alzheimer's disease with plaques and tangles: intracellular Abeta and synaptic dysfunction. Neuron 2003, 39:409-421

24. Miyakawa T, Yamada M, Duttaroy A, Wess J: Hyperactivity and intact hippocampus-dependent learning in mice lacking the M1 muscarinic acetylcholine receptor. J Neurosci 2001, 21:5239-5250

25. Jeon SJ, Rhee SY, Seo JE, Bak HR, Lee SH, Ryu JH, Cheong JH, Shin CY, Kim GH, Lee YS, Ko KH: Oroxylin A increases BDNF production by activation of MAPK-CREB pathway in rat primary cortical neuronal culture. Neurosci Res 2011, 69:214-222

26. Li XY, Zhan XR, Liu XM, Wang XC: CREB is a regulatory target for the protein kinase Akt/PKB in the differentiation of pancreatic ductal cells into islet beta-cells mediated by hepatocyte growth factor. Biochem Biophys Res Commun 2011, 404:711-716

27. Medeiros R, Baglietto-Vargas D, Laferla FM: The role of tau in Alzheimer's disease and related disorders. CNS Neurosci Ther 2010, [Epub ahead of press] doi: 10.1111/j.1755-5949.2010.00177.x

28. Medeiros R, Prediger RD, Passos GF, Pandolfo P, Duarte FS, Franco JL, Dafre AL, Di Giunta G, Figueiredo CP, Takahashi RN, Campos MM, Calixto JB: Connecting TNF-alpha signaling pathways to iNOS expression in a mouse model of Alzheimer's disease: relevance for the behavioral and synaptic deficits induced by amyloid beta protein. J Neurosci 2007, 27:5394-5404

29. Passos GF, Figueiredo CP, Prediger RD, Pandolfo P, Duarte FS, Medeiros R, Calixto JB: Role of the macrophage inflammatory protein-1alpha/CC chemokine receptor 5 signaling pathway in the neuroinflammatory response and cognitive deficits induced by betaamyloid peptide. Am J Pathol 2009, 175:1586-1597

30. Passos GF, Figueiredo CP. Prediger RD, Silva KA, Siqueira JM, Duarte FS, Leal PC, Medeiros R, Calixto JB: Involvement of phosphoinositide 3-kinase gamma in the neuro-inflammatory response and cognitive impairments induced by beta-amyloid 1-40 peptide in mice. Brain Behav Immun 2010, 24:493-501

31. Alkon DL, Sun MK, Nelson TJ: PKC signaling deficits: a mechanistic hypothesis for the origins of Alzheimer's disease. Trends Pharmaco Sci 2007, 28:51-60

32. Wei J, Walton EA, Milici A, Buccafusco JJ: m1-m5 muscarinic receptor distribution in rat CNS by RT-PCR and HPLC. J Neurochem 1994, 63:815-821

33. Gerber DJ, Sotnikova TD, Gainetdinov RR, Huang SY, Caron MG, Tonegawa S: Hyperactivity, elevated dopaminergic transmission, and response to amphetamine in M1 muscarinic acetylcholine receptordeficient mice. Proc Natl Acad Sci U S A 2001, 98:15312-15317

34. Kamsler A, McHugh TJ, Gerber D, Huang SY, Tonegawa S: Presynaptic $\mathrm{m} 1$ muscarinic receptors are necessary for mGluR long-term depression in the hippocampus. Proc Natl Acad Sci U S A 2010, 107:1618-1623

35. Hamilton SE, Loose MD, Qi M, Levey Al, Hille B, McKnight GS, Idzerda RL, Nathanson NM: Disruption of the $\mathrm{m} 1$ receptor gene ablates muscarinic receptor-dependent $\mathrm{M}$ current regulation and seizure activity in mice. Proc Natl Acad Sci U S A 1997, 94:1331113316

36. Hamilton SE, Nathanson NM: The M1 receptor is required for muscarinic activation of mitogen-activated protein (MAP) kinase in murine cerebral cortical neurons. J Biol Chem 2001, 276:15850-15853 
37. Levey Al: Muscarinic acetylcholine receptor expression in memory circuits: implications for treatment of Alzheimer disease. Proc Natl Acad Sci U S A 1996, 93:13541-13546

38. Stork O, Welzl H: Memory formation and the regulation of gene expression. Cell Mol Life Sci 1999, 55:575-592

39. Tischmeyer W, Grimm R: Activation of immediate early genes and memory formation. Cell Mol Life Sci 1999, 55:564-574

40. Lamprecht R: CREB: a message to remember. Cell Mol Life Sci 1999, 55:554-563

41. Tully T, Bourtchouladze R, Scott R, Tallman J: Targeting the CREB pathway for memory enhancers. Nat Rev Drug Discov 2003, 2: 267-277

42. von Linstow Roloff E, Platt B: Biochemical dysfunction and memory loss: the case of Alzheimer's dementia. Cell Mol Life Sci 1999, 55: $601-616$

43. Caccamo A, Fisher A, LaFerla FM: M1 agonists as a potential disease-modifying therapy for Alzheimer's disease. Curr Alzheimer Res 2009, 6:112-117

44. Bateman GA, Levi CR, Schofield P, Wang Y, Lovett EC: Quantitative measurement of cerebral haemodynamics in early vascular dementia and Alzheimer's disease. J Clin Neurosci 2006, 13:563-568

45. Grabowski TJ, Cho HS, Vonsattel JP, Rebeck GW, Greenberg SM: Novel amyloid precursor protein mutation in an lowa family with dementia and severe cerebral amyloid angiopathy. Ann Neurol 2001, 49:697-705

46. Natte R, Maat-Schieman ML, Haan J, Bornebroek M, Roos RA, van Duinen SG: Dementia in hereditary cerebral hemorrhage with amyloidosis-Dutch type is associated with cerebral amyloid angiopathy but is independent of plaques and neurofibrillary tangles. Ann Neurol 2001, 50:765-772

47. Selkoe DJ: Clearing the brain's amyloid cobwebs. Neuron 2001, 32:177-180

48. Weller RO, Massey A, Newman TA, Hutchings M, Kuo YM, Roher AE: Cerebral amyloid angiopathy: amyloid beta accumulates in putative interstitial fluid drainage pathways in Alzheimer's disease. Am J Pathol 1998, 153:725-733

49. Caccamo A, Oddo S, Tran LX, LaFerla FM: Lithium reduces tau phosphorylation but not A beta or working memory deficits in a transgenic model with both plaques and tangles. Am J Pathol 2007, 170:1669-1675

50. Sperber BR, Leight S, Goedert M, Lee VM: Glycogen synthase kinase-3 beta phosphorylates tau protein at multiple sites in intact cells. Neurosci Lett 1995, 197:149-153

51. Cruz JC, Tseng HC, Goldman JA, Shih H, Tsai LH: Aberrant Cdk5 activation by p25 triggers pathological events leading to neurodegeneration and neurofibrillary tangles. Neuron 2003, 40:471-483

52. Tsang SW, Pomakian J, Marshall GA, Vinters HV, Cummings JL, Chen CP, Wong PT, Lai MK: Disrupted muscarinic M1 receptor signaling correlates with loss of protein kinase $\mathrm{C}$ activity and glutamatergic deficit in Alzheimer's disease. Neurobiol Aging 2007, 28:1381-1387

53. Olds JL, Anderson ML, McPhie DL, Staten LD, Alkon DL: Imaging of memory-specific changes in the distribution of protein kinase $C$ in the hippocampus. Science 1989, 245:866-869

54. Kinouchi T, Sorimachi H, Maruyama K, Mizuno K, Ohno S, Ishiura S, Suzuki K: Conventional protein kinase C (PKC)-alpha and novel PKC epsilon, but not -delta, increase the secretion of an N-terminal fragment of Alzheimer's disease amyloid precursor protein from PKC cDNA transfected 3Y1 fibroblasts. FEBS Lett 1995, 364:203-206

55. Fang X, Yu S, Tanyi JL, Lu Y, Woodgett JR, Mills GB: Convergence of multiple signaling cascades at glycogen synthase kinase 3: edg receptor-mediated phosphorylation and inactivation by lysophosphatidic acid through a protein kinase C-dependent intracellular pathway. Mol Cell Biol 2002, 22:2099-2110

56. Delmas P, Wanaverbecq N, Abogadie FC, Mistry M, Brown DA: Signaling microdomains define the specificity of receptor-mediated InsP(3) pathways in neurons. Neuron 2002, 34:209-220

57. Rossi MA, Mash DC, DeToledo-Morrell L: Spatial memory in aged rats is related to PKCgamma-dependent G-protein coupling of the M1 receptor. Neurobiol Aging 2005, 26:53-68 